$$
\begin{gathered}
\text { WORKING PAPERS } \\
\text { No. } 27 / 2013(112) \\
\text { BARBARA LIBERDA } \\
\text { JOANNA TYROWICZ } \\
\text { MAGDALENA SMYK }
\end{gathered}
$$

AGE-PRODUCTIVITY PATTERNS IN TALENT OCCUPATIONS FOR MEN AND WOMEN: A DECOMPOSITION 


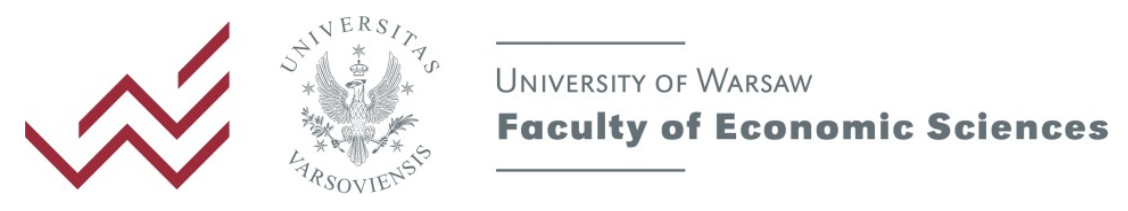

\title{
Age-productivity patterns in talent occupations for men and women: a decomposition
}

\author{
BARBARA LIBERDA \\ Faculty of Economic Sciences, \\ University of Warsaw \\ e-mail: barbara.liberda@uw.edu.pl
}

\author{
JOANNA TYROWICZ \\ Faculty of Economic Sciences, \\ University of Warsaw \\ National Bank of Poland \\ e-mail: j.tyrowicz@uw.edu.pl
}

\author{
Magdalena SMYK \\ Faculty of Economic Sciences, \\ University of Warsaw \\ e-mail:msmyk@wne.uw.edu.pl
}

\begin{abstract}
One could expect that in the so-called talent occupations, while access to these professions may differ between men and women, gender wage gap should be actually smaller due to high relevance of human capital quality. Wage regressions typically suggest an inverted U-shaped age-productivity pattern. However, such analyses confuse age, cohort and year effects. Deaton (1997) decomposition allows to disentangle these effects. We apply this method to inquire the age-productivity pattern for the so-called "talent" occupations. Using data from a transition economy (Poland) we find that indeed talent occupations have a steeper age-productivity pattern. However, gender differences are larger for talent occupations than for general occupations.
\end{abstract}

\section{Keywords:}

age-productivity pattern, gender wage gap, transition

JEL:

$\mathrm{J} 24, \mathrm{~J} 31, \mathrm{I} 20, \mathrm{~J} 71$ 


\section{Introduction}

In a recent paper, Hsieh, Hurst, Jones and Klenow (2013) argue that unequal access to talent professions lowered potential output in the United States by as much as $12 \%$. They identify talents with occupations requiring specialized (mostly tertiary) education, to which access was limited for women and racial minorities in the US until late 1960s due to acceptance quotas and segregation policies. While the racial context was quite specific to the case of the United States, barriers in accessing some occupations are frequent also with respect to gender. This may stem from both social norms and culture and taste base discrimination in the process of tertiary enrollment and school-to-work transition.

On the other hand, it has been identified in a number of studies that massive reallocation - associated either with technological change or with an economic transition - happen to be periods with increasing returns to talents and human capital, Card and DiNardo (2002); Munich, Svejnar and Terell (2005a, 2005b); Fleisher Sabirianova and Wang (2005); Goos and Manning (2007). There are both demand and supply factors which explain this phenomenon. Typically, better educated individuals are more flexible in adapting to the changing conditions, which explains why on average they "loose" less in the case of adverse shifts of labor demand. From the demand side, better educated individuals are generally preferred over less educated ones, which implies that high human capital is relatively more rewarded (even in the case of downward real adjustment in wages). Polish experience combines both these phenomena. From the perspective of the gender and talents literature, it is clear that lowering labor force participation in the period of economic transition reflected at least partially toughening market conditions and emerging barriers in grasping some jobs. From the perspective of reallocation, one should in principle expect that returns to human capital and talents are the key determinant, diminishing the space for potential gender-based discrimination. The objective of this paper is to analyze if the persistence of the gender wage gap in Poland reflects differences across genders on how the ageproductivity patterns evolve or rather the compositional issues (e.g. women being out of labor force in more productive periods of the life cycle).

To answer this question we construct an age-productivity curve using decomposition techniques. We do the analysis for the general population and separately for the so-called talent occupations. The contribution of this paper is threefold. First, to the best of our knowledge, the analysis of age-productivity patterns are rare in gender context and we are not aware of any study that would elaborate that particular angle. Similarly - and this is the second contribution - typically the talent occupations aspect is missing from both gender and productivity analyses. While clearly tertiary education delays labor market entry and is typically associated with longer activity afterwards, 
this could be possibly justified by a relative increase of returns to human capital towards the end of the professional activity. If that indeed is the case, low labor force participation by elderly women in Poland would be at odds with the labor market incentives. Finally, this paper builds and explores an extremely large data set for Poland, performing - to our best knowledge - first analysis of- age-productivity patterns, which account for cohort and year effects.

This paper is structured as follows. The next section presents insights from two strands of the literature which are typically treated separately: the literature on ageproductivity patterns and the gender gap literature. We subsequently move to describe in detail the Deaton decomposition and the way it was applied in our study. We then present the data and data properties. The results reveal that while age-productivity pattern is generally steeper in talent occupations, the gender gap is larger for these professions. In the concluding section we derive policy recommendations and suggest some avenues for future research.

\section{Insights from the literature}

This literature review combines two strands of literature. First we discuss the developments in decomposition methods used in the analyses of age-productivity patterns. The literature in this field is not vast, but multiplicity of approaches exist, which calls for a justification on why Deaton (1997) methodology is followed in this paper. Second, we also point to the relevance of distinguishing talent occupations in analyzing the gender wage gap.

Thinking about life cycle patterns in terms of separate age, cohort and period effects has recently become very popular in scientific literature. Subjects of this type of analysis are most of all consumption (Fernandez-Villaverde and Krueger, 2007), savings (Paxson, 1996; Parker, 1999) and income (among others: Thornton et al, 1997; Deaton and Paxson, 1994; Beaudry et al, 2000; Fokuda, 2008). In this review we concentrate on papers with various methods of showing how age, cohort and year factors relate to (especially) earnings profiles. As Thornton et al. (1997) argues there are four factors influencing individual income patterns: inflation, general productivity growth in the economy, individual productivity growth and the effect of birth cohort. The rate of inflation and average productivity in whole economy is known as period (or time) effect and shows how earnings change through subsequent years. Individual productivity growth corresponds to the age effect, which combines, among others, job experience and human capital gained during the whole lifetime. Last factor - cohort effects - is related with many things affecting earning patterns. One of them is cohort size, e.g. those who were born during the so-called "baby-boom" may earn less than those from a different cohort (Welch, 1979). 
Estimating age, cohort and year effects at the same time suffers from an identification problem. By definition, time variable equals age plus birth cohort. In principle, the identification problem is addressed by the means of two methodological tricks: the so-called synthetic cohorts or the decomposition techniques. We discuss them below.

Survey data make it possible to construct so-called pseudo-panels ${ }^{1}$. Observing a population in one dataset that is identical in all characteristics but age to a population observed in a previous wave of the survey allows for the construction of a pseudo-panel for which statistics such as group means or medians may be computed and compared. Synthetic cohorts are based on such groups, which enables identification of time series with age and time effects. This method - known as synthetic cohort technique or simply a pseudo-panel - was created by Browning, Deaton and Irish (1985), and subsequently developed by Heckman and Robb (1985). It is typically used for analyzing the consumption and savings patterns from household data, e.g. Gourinchas, Parker (2002) as well as Fernandez-Villaverde and Krueger (2002). Beaudry et al. (2000) presents differences between cohorts in earnings patterns in Canada. They find no substantial changes for women and a decreasing trend in wages for men. The same pattern was observed for high school graduates and university graduates. Fitzenberger et al. (2004) find much lower wage growth for females through life cycle and no cohort effects for female earnings in Germany; Fitzenberger and Kohn (2006) also claim that nominal wage reduction rate is higher the lower the occupation skill level. For income pattern analysis in Poland, synthetic cohort technique was used by Kolasa (2012) - her results indicates hump-shaped life cycle age-variance profile of earnings. Although this approach is often useful, it is inconvenient if the time series are short.

Second method is based on additional assumption, made by Deaton (1997), which allows using all three dummies (age, year, birth cohort) in one regression. Following the life-cycle income hypothesis, time effects are orthogonal to a time trend and their sum can be normalized to zero. We apply this method model in our study and more details are presented in the next section.

The approach first developed by Deaton is also the basis for the model constructed by Attanasio (1998) and Parker (1999), who used it to decompose saving behavior of American citizens. Additionally, Attanasio (1998) justifies assumption about time effects with arguments related to the nature of savings and earnings. The advantage of the decomposition technique over synthetic cohort lies in how information hidden in the data is used. Age-productivity profile encompasses in general 40-50 years

\footnotetext{
${ }^{1}$ Please note, that panel data facilitate identification of the rate at which productivity on average changes with age, but not really the separation of age, cohort and year effects.
} 
of time span, while the availability of the micro-level data for many countries typically encompasses few, at best 20 years of data. Synthetic cohorts suffer from the fact that one particular group could only be identified 20 times, whereas it is the duration of 40 to 50 years that is of interest. Decomposition such as the one proposed by Deaton (1997) clearly does not make up for the unavailable periods (and thus data). However, since the analysis is based on a regression, the relationship between the age and the earnings is identified by the means of a functional approximation. Thus, the interpretation is somewhat stronger, Attanasio (1998).

Empirical analysis of earning profiles based on Deaton decomposition reveals that age-productivity profiles differ between countries and types of economies. Deaton and Paxson (1994) show how age, cohort and year influence earning, consumption and saving profiles in Taiwan. They find that income is steadily rising with age throughout the life cycle. Cohort effects decrease for older cohorts which means that those born earlier earn less than those from subsequent cohorts. It is expected from emerging economies like Taiwan. Meanwhile, Blisard (2001) who decompose incomes in United States, find negative and decreasing cohort effects and hump-shaped age profile.

In addition to the two main techniques - synthetic cohorts and orthogonal decomposition - some studies rely on additional methods. Beaudry and Lemieux (1999) adopted assumption that that time effect can be replaced by a proxy. They do that in a female labor force participation cohort analysis. In Beffy and Bonnet (2011) wealth decomposition, housing prices were used as a time proxy in estimation. Finally, Fokuda (2008) estimates age, cohort and period effects on American wages using Bayesian cohort modeling. According to his results age effect is significant for high school graduates and grows until the age of 47. After that point wages start decreasing. For college graduates no downward trend is observed. Cohort effects are negligible for all population and period effect (downward sloping) is significant only for high school graduates.

Summarizing, there are two main methods of dealing with the problem of linear dependency between calendar year, age and cohort. Of the two, decomposition technique developed by Deaton is less demanding in terms of data than synthetic cohorts technique. While external validity is stronger the higher the quality of the data, approximation by the decomposition techniques relies on estimating patterns rather than extending the trends observed over shorter durations. Thus, it is the Deaton (1997) approach that we follow in this paper. Also, the assumption that year effects are orthogonal to a time trend and a normalization of time variable is consistent with the nature of income patterns, Attanasio (1998).

Summarizing this part, while typical Mincer-style regressions find universally an inverted U-shaped profile for age and productivity, decomposition studies support a 
wider class of patterns. Namely, transition economies as Taiwan seem to demonstrate a steadily increasing pattern. Mature industrialized countries as Canada, US and Japan show a slightly downward sloping pattern, while in some specific cases even a negative pattern was found. While the origins of this diversity in patterns may stem from a number of different sources, the literature shows that patterns for university graduates differ from the rest of the working population. This finding lends support to the relevance of our research question.

Also the gender wage gap literature lends support to our study. Namely, many studies find that gender wage gap (corrected for differences in endowments) differs along the wage distribution. The findings for Italy suggest that discrimination (i.e. adjusted wage gap) is largest for highest and lowest income women, Picchio and Mussida (2011). Similar findings were confirmed for Spain, De la Rica, Dolado and Llorens (2008). Also some other European countries as well as the US seem to exhibit similar pattern, Olivetti and Petrongolo (2008). In fact, there is a considerable body of evidence for the so-called "sticky floors" and "glass ceilings" across many countries, Arulampalam, Booth and Bryan (2007); Christofides, Polycarpou, and Vrachimis (2010).

Part of the literature attempting to explain this asymmetry point to the educational system and unequal access to education. The problem was demonstrated to be particularly pronounced in developing countries, Emiliani and Baron (2012). In industrialized countries, on the other hand, the literature seeks to explain the asymmetry in the gender wage gap by sorting of workers (e.g. Antonczyk, Fitzenberger, and Sommerfeld, 2010) and differences in risk preferences (e.g. Niederle and Vesterlund, 2007; Booth, Cardona and Nolen, 2011; Booth and Nolen, 2012).

In addition, vast body of literature analyzes differences in managers compensations, Murphy (1999); Bell (2005); Cardoso and Winter-Ebner (2007). Gender discrimination was found, among others, in the case of Denmark (Smith, Smith and Verne, 2010), US (Blair-Loy, 1999 and 2001; Bertrand and Hallock, 2001) Germany (Busch and Holst, 2009) and Sweden (Albrecht, Björklund, Vroman, 2003). Literature is particularly rich on US and Danish managers and finance professionals, finding important consequences of child bearing and family on female careers, e.g. Blau and Kahn (2005), Gutierrez-Domenech (2005). Using data from Global Entrepreneurship Monitor, Estrin and Mickiewicz (2011) find that also self-employment among female is differentiated across countries and replies to the extent of how "gendered" is the institutional system in the country (e.g. freedom of mobility).

Thus, there are at least two important reasons to compare differences in ageproductivity patterns across genders, with special emphasis on talent occupations. First, university graduates seem to exhibit differences in age-productivity patterns when compared to the rest of the working population. Except for the trivial delay in 
commencing the professional carrier, the main reason for why such differences could emerge is differences in returns to experience in occupations requiring tertiary education. Second, it seems that gender differences in talent occupations are particularly relevant. We will put these two motivations into an empirical test in subsequent sessions.

\section{Method}

This paper employs Deaton (1997) decomposition. This method decomposes the overall effect to three sets of dummies: for the year, for the age and for the cohort. These dummies are orthogonalized, so that the estimated effects were interpreted directly. The method consists of estimating a simple regression:

$$
w_{j, t}=\sum_{t=1}^{T} \alpha_{t} \text { year }_{t}+\sum_{j=25}^{60} \beta_{j} \text { age }_{j}+\sum_{i=8}^{43} \gamma_{i, t=1995} \text { cohort }_{i, t=1995}+\varepsilon_{j, t},
$$

where $j$ is the age identifier and $t$ denotes time. Estimation $\beta$ conditional on $\alpha$ and $\gamma$ parameters allows the identification of the age effects controlling for time and cohort effects. Cohort is typically identified as age at some period identical for all individuals in a study. In the case of this study the cohort is defined as age in 1995, which is the first year of available reliable individual level data for Poland. The boundaries for the cohort are established naturally henceforth. Since the most recent data concerns 2012 and the youngest individual from that year is a 25-year old, that person was 8 years old in 1995 . We do not analyze individuals under 25 years of age because we are mostly interested in comparing individuals with tertiary education in talent occupations to those who are not in this group. Since labor force participation among elderly is very low in Poland, we limit our sample to individuals younger than 60 years of age.

Because of collinearity between age, cohort and year variables ( $\operatorname{cohort}=1995-$ (year-age) ), we need to use assumption (following Deaton), that year effects are orthogonal to a time trend and that their sum is normalized to zero. For this purpose new year dummy is created as:

$$
d_{t}=\sum_{i=1995}^{2012} \text { year }_{t}-(t-i) \text { year }_{i}
$$

where year $_{t}$ is a dummy, which takes one if observation is from year $t$. We also have to drop first column from the cohort and age dummy matrices and the first- and secondyear dummy variables. Coefficients for the first and second year can subsequently be recovered based on the assumption that all time effects equals zero.

While decomposition itself brings about few methodological choices, the sample on which Deaton (1997) decomposition is performed requires more justification. It is standard to perform decomposition on the total available sample. However, with such 
specification it is impossible to derive information about the cohort and age effects separately for some groups. Please note also, that including additional (individual) explanatory variables violates the orthogonality requirement, thus undermining the decomposition validity.

In this paper we propose to amend the standard approach by including decompositions on subsamples, relevant from the point of view of our research question. Namely, we suggest to separately look at genders and in addition to separately include estimates for the so-called "talents". In total, we repeat the decomposition six times: (i) overall population, (ii) males and (iii) females, with additional specification of each of the three decompositions for the "talent" occupations.

Identification of "talent" occupations follows from Hsieh et al (2012). We coded as "talent" occupations top three levels in International Standard Classification of Occupations (ISCO), i.e.

- legislators, senior officials and managers;

- professionals;

- technicians and associate professionals

However, we additionally imposed the requirement of tertiary educational attainment. This choice was dictated by the basic logic behind the identification of problem diagnosed in Hsieh et al (2012), i.e. barriers in access to some professions. In many "talent" occupations, education is a necessary prerequisite (e.g. lawyers, doctors, architects).

We are presenting decomposition results on graphs showing separate age, cohort and year coefficients. This form allows interpreting most interesting patterns: how income dynamic changes with age and if this paths are different for people born in different times.

\section{Data}

This paper relies on Polish Labor Force Survey data from 1995q1 until 2012q4. In total we use 72 quarterly samples with roughly 2.2 million observations in total. Naturally, the final sample is substantially smaller. First, in each quarter we considered individuals aged above 25 and below the de iure retirement age. This choice is dictated by the fact that under 25 years of age it is rare to possess tertiary education, while inclusion of outliers, i.e. individuals who perform some of the "talent" occupations not requiring university diploma at very young age could flaw our results. Secondly, participation rates are low in Poland, while unemployment has been relatively high. Consequently, wages are observed for a relatively small population. Finally, in Polish LFS, wage data is self-reported net income. It is only available for wage employed 
individuals and is coupled with information on hours worked per week. Using these two self-reported indicators we computed hourly wage. Neither wages nor hours worked are available for the self-employed and the helping family members. Since women relatively more frequently are employed part-time, not accounting for actual hours worked would impose a considerable bias. Thus, in fact the study includes all individuals aged between 25 and retirement age, wage employed, for whom data on hours worked was available. This narrowed sample to roughly 437000 observations.

For the purposes of comparison, wage data were deflated with a chain index based on a quarterly CPI as reported by Central Statistical Office. Deflation is a necessary precondition because otherwise cohort effects could be confounded with increase in wages due to overall increases in prices.

Table 1. Descriptive statistics

\begin{tabular}{l|c|c|c|c} 
Variable & Mean total & Mean females & Mean talented & Mean talented females \\
\hline Age & 40.6 & 40.61 & 39.8 & 39.3 \\
\hline Females & $47.3 \%$ & $100 \%$ & $59.6 \%$ & $100 \%$ \\
\hline Primary & $8 \%$ & $7.5 \%$ & - & - \\
\hline Secondary & $69 \%$ & $63.6 \%$ & $100 \%$ & $100 \%$ \\
\hline Tertiary & $23 \%$ & $28.9 \%$ & 20.18 PLN & 19.55 PLN \\
\hline Hourly wage & 12.06 PLN & 11.47 PLN & $100 \%$ & $100 \%$ \\
\hline "Talent" & $15.9 \%$ & $20.4 \%$ & 107414 & 64439 \\
\hline
\end{tabular}

Table 1 presents the descriptive statistics of our sample. While women are on average much better educated than men in the sample, it should be noted that overall educational attainments have been constantly increasing over the analyzed period. In fact, as reported in Figure 1, the share of individuals with tertiary education nearly doubled over the analyzed period. In fact, this could be a source of bias, because in principle in each consecutive cohort the share of "more productive" individuals is higher, which could be confounded with simple cohort effects. However, the objective of this study is not that much to provide isolated estimates of cohort effects, as to compare the estimates of cohort effects across analyzed samples. 
Figure 1. Educational attainment

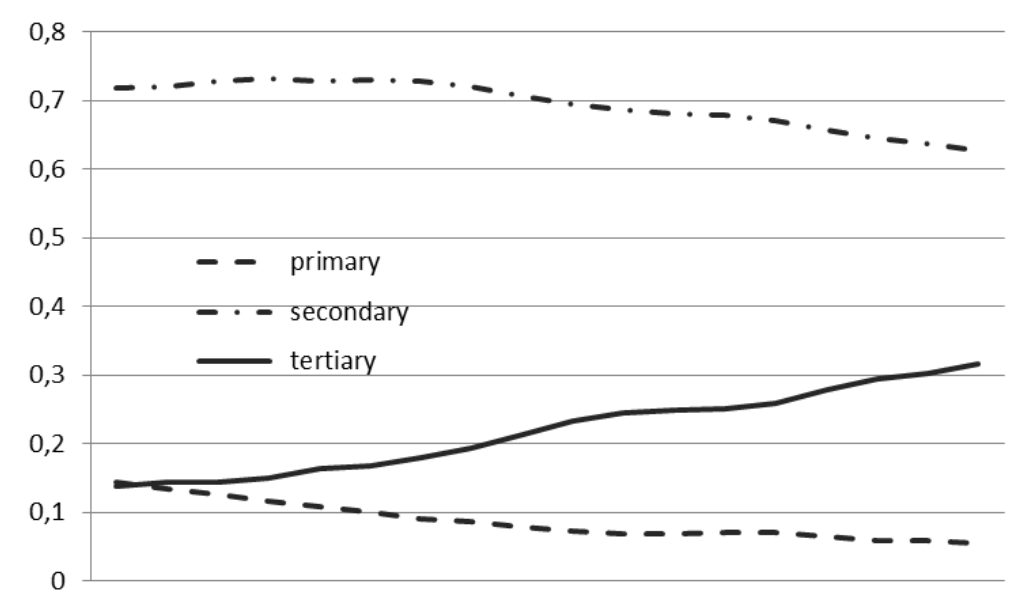

In our final sample high-skilled occupation are performed on average by 15 percent of all workers. This share is rising every year; it is also higher for women approximately 20 percent. Men on average are less educated and definitely less frequently working in "talent" occupation. As expected, hourly wages for talent group are higher than in whole population, approximately about $75 \%$. Talented people are also about one year younger than total mean and what is more, women, who represent two thirds of this specific group, are even younger than men.

\section{Results}

The results of the decomposition of wages into the cohort effects, age effects and year effects are exhibited on 3 plots of Figure 2. Year effects are consistent with business cycle, showing a boom in the late 1990s and a decline in turbulent years 2003-2005 before and after Poland's joining the European Union in 2004. There was a second boom in 2008-2009 followed by a decline, caused by financial crisis which was delayed in Poland. Age and cohort effects are fairly inverse, which suggests that indeed the shift in demand for skills in Poland has changed considerably due to the economic transition. Age effects are increasing sharply between 25 and 50. This pattern is similar to the one identified by Deaton and Paxson (1994). After that threshold, the growth is slower, but the slope continues to be positive.

The shape of this relationship could be affected by extremely early labor market exits in Poland. To test the susceptibility of the findings to this phenomenon - as discussed earlier - we estimated the decomposition also for people de iure in the labor force, but de facto not earning income. This has increased the size of the sample from roughly 435000 to roughly 650000 . The lines estimated for specifications imputing zero earned incomes to the unemployed and inactive do exhibit differences along all the dimensions. First, age effects are more linear when zeros are included. Second, cohort effects estimated without zeros flatten for older generations, whereas the specification 
including imputed zero earned incomes does not ${ }^{2}$. Finally, year effects display less variability in earlier years, but are fairly common in the recent period. Thus, while the year effects are clearly different reflecting the cyclical properties of the unemployment, the shapes of age and cohort effects are similar. This suggests that the focus on individuals for whom all variables are available does not seem to bias substantially the conclusions from this study. In the subsequent analysis we focus on a specification without imputed earned income, while the interested reader can keep in mind the correction necessary to relatively low labor force participation in Poland.

Figure 2. Deaton decomposition for the entire sample

Year effects

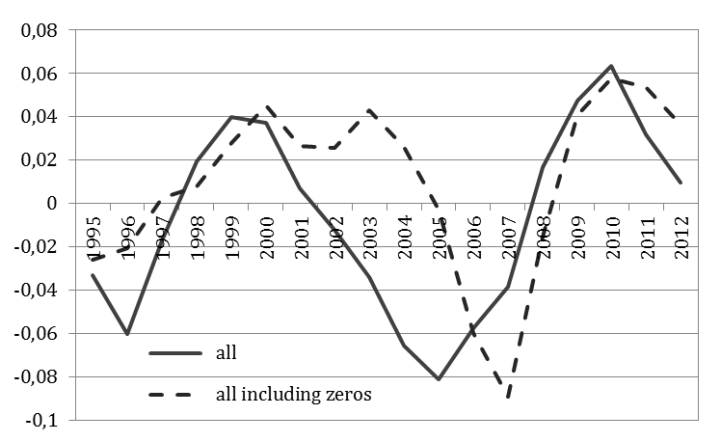

Cohort effects

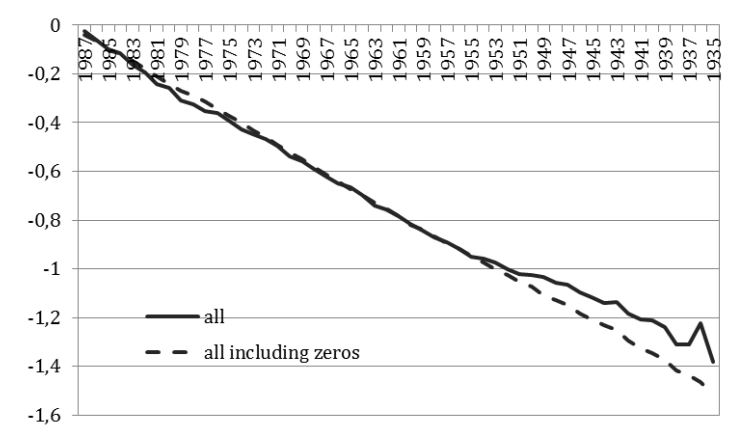

Age effects

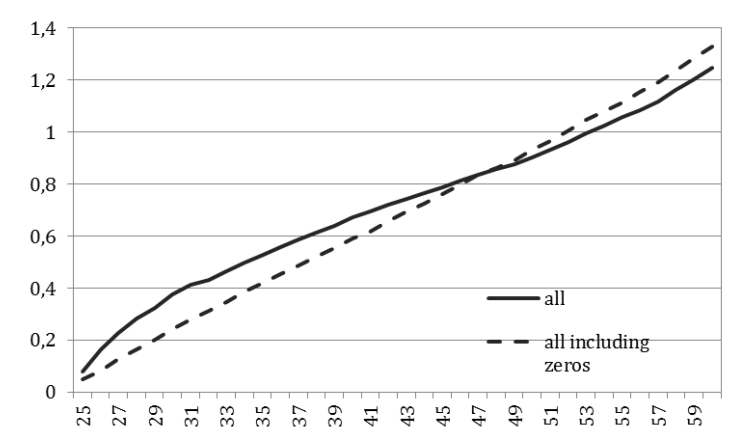

Note: estimates from equation (1). 'All' denotes total working population for which income data and hours data are available. 'All including zeros' denotes regressions for all labor force participants (including the unemployed and the so called NEETs, for whom zeros were imputed). Cohort described by age in 1995

Figure 3 shows on the left plot that there is no difference between male and female age-productivity pattern in the whole population. However income of talented individuals grows faster - by 7,6 percentage points for thirty-year-old and almost 20 percentage for fifty-year-old, as the right plot demonstrates. The differences between men and women life cycle income are visible in talented groups (bottom plot). In fact, talented males earnings grow faster with age throughout the life cycle than earnings of talented women. Till the age of thirty the paths are the same for these two groups. Later in age the dynamics of income of talent men and talent women start diverging. This is

\footnotetext{
${ }^{2}$ Due to the early retirement schemes in Poland till 2010 many individuals retired in their early 50s. Consistent with this is positive self-selection into employment, which may explain the difference between the estimates with and without imputed zero earned incomes.
} 
age when women slow down or break their careers to have and rear children. After a break their earnings do not catch up with males income ${ }^{3}$. There are potentially many sources of this divergence. On the one hand, division of labor continuous to be traditional in many households, which makes women invest more time in child rearing and less in career. By the same token, employers may discount the probability of higher absenteeism of mothers. On the other hand, such finding is also consistent with gender discrimination and glass ceilings. While the paper makes no judgment on quantitative role of these processes, it points out that the divergence starts at the age of about 30 , which is an important observation from the policy perspective.

Figure 3. Deaton decomposition for the subsamples.

Age effects: men and women

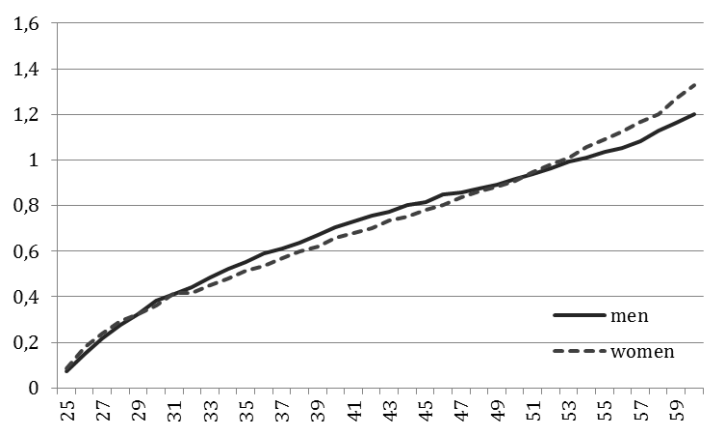

Age effects: talent occupations, men $\&$ women

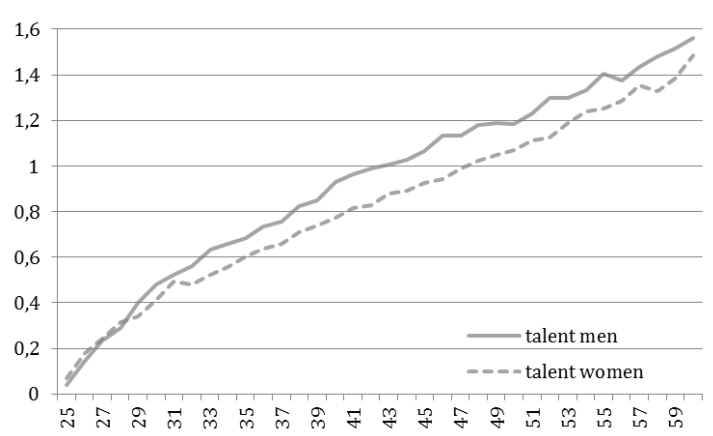

Age effects: talent \& general occupations

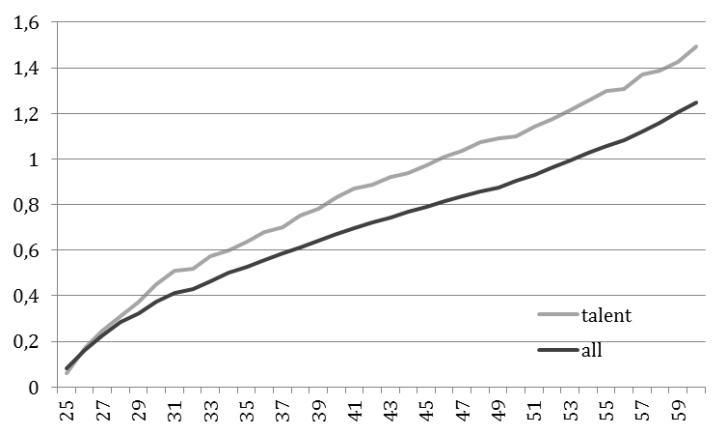

Note: estimates from equation (1). Talent defined as top three occupations in ISCO coding with tertiary education. Specification without imputed zero earned income. Estimates for separate subpopulations. Cohort effects estimated but not reported for brevity (available upon request).

In order to provide a quantitative evaluation of the size of the gap between men and women we performed an Oaxaca-Blinder (1973) decomposition for the simple regression, as presented in equation (1), Table 2. Clearly, this is just a tool to "integrate" the difference between solid and dashed lines over the cohort, age and year domains. We are not attempting any interpretations in terms of discrimination based on this decomposition. The estimates confirm that the gap between genders persists and that it is not a consequence of the composition effects, at least not vis-à-vis the variables

\footnotetext{
${ }^{3}$ According to the household budget surveys data for Poland, the contribution of female partner income to the total couple income during the life cycle is lower than her partner share by one third, even if both are tertiary educated and of the same age (Liberda and Peczkowski, 2013).
} 
included for the Deaton (1997) decomposition. The average difference of ageproductivity pattern between men and women is 10 percentage points. This is almost entirely attributable to the shape of the age-productivity pattern (as well as year and cohort).

The results are virtually the same for the total sample and among individuals in "talented" occupations. In the total sample the raw wage gap between genders amounts to $10.2 \%$ whereas it is $9.4 \%$ among the "talent" occupations. When accounted for potential composition effects, the gap (adjusted) increases in both cases to $10.5 \%$ of the male hourly wage. While the estimated gap is highly statistically significant in each estimation, the difference between them is not.

Table 2. Oaxaca-Blinder (1973) decomposition results

\begin{tabular}{l|cc} 
& Total sample & Talent occupations \\
\hline Raw & $0.102^{* * *}$ & $0.094^{* * *}$ \\
difference & $(0.002)$ & $(0.004)$ \\
\hline Attributable to & $-0.0012^{* *}$ & $-0.012^{* * *}$ \\
endowments & $(0.001)$ & $(0.002)$ \\
\hline Attributable to & $0.105^{* * *}$ & $0.106^{* * *}$ \\
coefficients & $(0.001)$ & $(0.004)$ \\
\hline Attributable to & $-0.003^{* * *}$ & -0.0002 \\
interactions & $(0.000)$ & $(0.001)$ \\
\hline No. of observations & 677229 & 107414 \\
\hline
\end{tabular}

Note: Oaxaca-Blinder decomposition, standard errors in parentheses, significance denoted by ${ }^{* *} \mathrm{p}<0.01,{ }^{* *} \mathrm{p}<0.05,{ }^{*} \mathrm{p}<0.1$, respectively. Results from regression (1).

Given the divergence emerging from Figure 3 and the lack of it in Table 2, the results seem to suggest that talent occupations are characterized not only by different patterns of age-productivity patterns across genders, but also by different year and cohort effects. In fact, the differences in age and year effects quantitatively average out in Oaxaca-Blinder decomposition, Figure 4. Indeed, contribution from a different valuation of age across genders start at the age of about 30 , but are substantially higher in the case of "talent" occupations, more than doubling the estimates of the contributions to the gap for the general population. Moreover, towards the 50s, women age contribution tends to be negative for the total population, but is insignificant or positive for the "talent" occupations. 
Figure 4. Estimates of the contribution from the age effects to gender wage gap

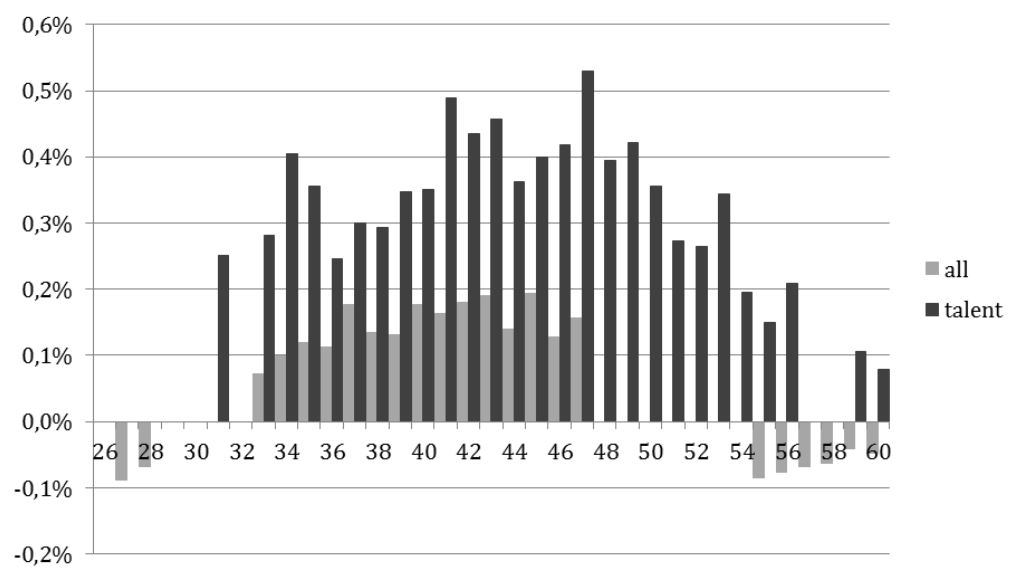

Note: estimates of contributions to the gender wage gap from OaxacaBlinder (1973) decomposition based on equation (1). Specification without imputed zero earned income. Talent defined as top three occupations in ISCO coding with tertiary education. Estimates for two separate subpopulations. Insignificant estimates reported as zeros (no bars in the graph).

Summarizing, while the overall age-productivity pattern is increasing across both genders, the growth is steeper for men in the case of talent professions. Please, note that these estimates do not take into account any individual level or firm characteristics, which implies that they cannot be used as reliable proxies for the gender wage gap, as typically referred to in the literature.

\section{Conclusions}

In a study that will surely become influential, Hsieh et al. (2013) demonstrate that constraints on access to what they label as "talent" occupations are costly. This cost stems from the fact, that "talents" remain underutilized, if legal or cultural barriers block some professions for women or minorities. While formal constraints on access to professions are clearly an important area of analysis, if returns to investment in education necessary to perform the "talent" professions are lower for some groups, then clearly that group will tend to underinvest in skills relative to the social optimum. This was the starting point for our analysis in this paper.

We use Deaton (1997) decomposition for the so-called "talents" in order to obtain age-productivity profiles for men and women separately. Deaton (1997) decomposition allows to separate age effects from cohort and year effects. We used the data for a transition economy (Poland) and analyzed if the persistence of the gender wage gap in Poland reflects differences across genders on how the age-productivity patterns evolve or rather the compositional issues (e.g. women being out of labor force in more productive periods of the life cycle).

This paper performs - to our best knowledge - the first analysis of age productivity patterns in gender context which accounts for cohort and year effects. We find that age effects are generally increasing, while the rate of growth flattens after 50 . "Talent" occupations in general have a steeper age-productivity pattern. However, 
"talented" males' earnings grow with age throughout the life cycle faster than earnings of talented women, while the divergence starts about 5 years after the start of the professional carrier, a period also associated with child bearing. In fact, until the age of thirty the paths of age-productivity patterns are the same for both genders and it is only later when they start diverging for men and women in "talent" occupations. Additional decomposition reveals that this effect is statistically significant for both "talent" and other occupations, but is quantitatively much larger for the former.

One of the important limitations of our study is the fact that we only use 18 years of data, while a large part of this period comprises transition from a centrally planned to a market economy. Massive labor reallocation and relatively high unemployment associated with these processes could have considerably affected our findings. While the estimated year effects are low when compared to age effects, the mass processes could have exhibited themselves also in cohort and year effects. Thus, to test whether our findings can be generalized to non-transition economies, it would be commendable to encompass mature, industrialized countries. 


\section{References}

Albrecht, J., Björklund, A., Vroman, S. (2003). Is there a glass ceiling in Sweden? Journal of Labor Economics, 21(1), 145-177.

Antonczyk, D., Fitzenberger, B., Sommerfeld, K. (2010). Rising wage inequality, the decline of collective bargaining, and the gender wage gap. Labour Economics, 17(5), 835-847.

Arulampalam, W., Booth, A. L., Bryan, M. L. (2007). Is there a glass ceiling over Europe? Exploring the gender pay gap across the wage distribution. Industrial and Labor Relations Review, 163-186.

Attanasio, O. P. (1998). Cohort Analysis of Saving Behavior by US Households. Journal of Human Resources, 33(3), 575-609.

Beaudry, P., Lemieux, T. (1999). Evolution of the female labour force participation rate in Canada, 1976-1994: A cohort analysis. Applied Research Branch, Human Resources Development Canada.

Beaudry, P., Green, D. A. (2000). Cohort patterns in Canadian earnings: assessing the role of skill premia in inequality trends. Canadian Journal of Economics/Revue canadienne d'économique, 33(4), 907-936.

Beffy, M., Bonnet, C. (2001) Wealth evolution over the life cycle: an age-period-cohort decomposition.

Bell, L. A. (2005). Women-led firms and the gender gap in top executive jobs (No. 1689). IZA Discussion Papers.

Blair-Loy, M. (1999). Career Patterns of Executive Women in Finance: An Optimal Matching Analysis 1. American Journal of Sociology, 104(5), 1346-1397.

Blair-Loy, M. (2001). Cultural Constructions of Family Schemas: The Case of Women Finance Executives. Gender and Society, 687-709.

Blau, F. D., Kahn, L. M. (2007). Changes in the Labor Supply Behavior of Married Women: 19802000. Journal of Labor Economics, 25(3).

Blisard, N. (2001). Income and Food Expenditures Decomposed by Cohort, Age, and Time Effects (No. 33552). United States Department of Agriculture, Economic Research Service.

Booth, A., Sosa, L. C., Nolen, P. (2011). Gender Differences in Risk Aversion: Do Single-Sex Environments Affect their Development?.

Booth, A., Nolen, P. (2012). Choosing to compete: How different are girls and boys?. Journal of Economic Behavior \& Organization, 81(2), 542-555.

Browning, M., Deaton, A., Irish, M. (1985). A profitable approach to labor supply and commodity demands over the life-cycle. Econometrica: Journal of the Econometric Society, 503-543.

Busch, A., Holst, E. (2009). Glass ceiling effect and earnings: the gender pay gap in managerial positions in Germany (No. 905). Discussion papers // German Institute for Economic Research.

Card, D. E., DiNardo, J. E., (2002), Skill-Biased Technological Change and Rising Wage Inequality: Some Problems and Puzzles, Journal of Labor Economics, 20, issue 4, p. 733-783.

Cardoso, A. R., Winter-Ebner R. (2007), Mentoring and Segregation: Female-Led Firms and Gender Wage Policies, IZA DP No. 3210, Bonn.

Christofides, L., Polycarpou, A., Vrachimis, K. (2010). The gender wage gaps, 'sticky floors' and 'glass ceilings' of the European Union.

De la Rica, S., Dolado, J. J., Llorens, V. (2008). Ceilings or floors? Gender wage gaps by education in Spain. Journal of Population Economics, 21(3), 751-776.

Deaton, A., Paxson, C. (1994). Saving, growth, and aging in Taiwan. In Studies in the Economics of Aging (pp. 331-362). University of Chicago Press.

Deaton, A. (1997). The analysis of household surveys: a microeconometric approach to development policy. World Bank Publications.

Emiliani C. L., Baron, J. D. (2012). Educational segregation and the gender wage gap for recent college graduates in Colombia.

Fernandez-Villaverde, J., Krueger, D. (2007). Consumption over the life cycle: Facts from consumer expenditure survey data. The Review of Economics and Statistics, 89(3), 552565. 
Fleisher, B. M. Sabirianova, K., Wang, X., (2005). Returns to skills and the speed of reforms: Evidence from Central and Eastern Europe, China, and Russia, Journal of Comparative Economics, Elsevier, vol. 33(2), pages 351-370, June.

Fitzenberger, B., Schnabel, R., Wunderlich, G. (2004). The gender gap in labor market participation and employment: A cohort analysis for West Germany. Journal of population economics, 17(1), 83-116.

Fitzenberger, B., Kohn, K. (2006). Skill Wage Premia, Employment, and Cohort Effects: Are Workers in Germany All of the Same Type?

Fukuda, K. (2008). A Cohort Analysis Of Us Age-Earnings Profiles. Bulletin of Economic Research, 60(2), 191-207.

Gourinchas, P. O., Parker, J. A. (2002). Consumption over the life cycle. Econometrica, 70(1), 4789.

Goos, M., Manning A., (2007). Lousy and lovely jobs: The rising polarization of work in Britain. The Review of Economics and Statistics 89.1, 118-133.

Gutierrez-Domenech, M. (2005). Employment after motherhood: a European comparison. Labour Economics, 12(1), 99-123.

Hallock, K., Bertrand, M. (1999). The Gender Gap in Top Corporate Jobs. Industrial and Labor Relations Review, 55(1).

Heckman, J., Robb, R. (1985). Using longitudinal data to estimate age, period and cohort effects in earnings equations. In Cohort analysis in social research (pp. 137-150). Springer New York.

Hsieh, C. T., Hurst, E., Jones, C. I., Klenow, P. J. (2013). The allocation of talent and US economic growth, (No. w18693). National Bureau of Economic Research.

Kolasa, A. (2012). Life cycle income and consumption patterns in transition. National Bank of Poland Working Paper, (133).

Liberda, B., Peczkowski, M. (2013). Life cycle income of married and cohabited women and men. Conference paper Current Economic and Social Topics CEST'2013, Warsaw, 23-24 May.

Munich, D., Svejnar, J., Terrell, K., (2005a). Is women's human capital valued more by markets than by planners?, Journal of Comparative Economics, Elsevier, vol. 33(2), pages 278-299, June.

Münich D., Svejnar J., Terrell K., (2005b). Returns to Human Capital Under The Communist Wage Grid and During the Transition to a Market Economy, The Review of Economics and Statistics, MIT Press, vol. 87(1), pages 100-123, February.

Mickiewicz, T. M., Estrin, S. (2011). Institutions and female entrepreneurship. Small Business Economics, 37, 397-415.

Murphy, K. J. (1999), Executive Compensation'. In Ashenfelter, O. and D. Card (eds.), Handbook in Labor Economics. Elsevier, Amsterdam, North Holland, 2485-2563.

Niederle, M., Vesterlund, L. (2007). Do women shy away from competition? Do men compete too much?. The Quarterly Journal of Economics, 122(3), 1067-1101.

Parker, J. A. (1999). Spendthrift in America? On two decades of decline in the US saving rate. In NBER Macroeconomics Annual 1999, Volume 14 (pp. 317-387). MIT.

Paxson, Ch. (1996), Saving and Growth:_Evidence from Micro Data. European Economic Review 40(2): 255-288.

Picchio, M., Mussida, C. (2011). Gender wage gap: A semi-parametric approach with sample selection correction. Labour Economics, 18(5), 564-578.

Petrongolo, B., Olivetti, C. (2008). Unequal pay or unequal employment? A cross-country analysis of gender gaps.

Smith, N., Smith, V., Verne, M. (2011). The gender pay gap in top corporate jobs in Denmark: Glass ceilings, sticky floors or both?. International Journal of Manpower, 32(2), 156-177.

Thornton, R. J., Rodgers, J. D., Brookshire, M. L. (1997). On the interpretation of age-earnings profiles. Journal of Labor Research, 18(2), 351-365.

Welch, Finis. The Effects of Cohort Size on Earnings: The Baby Boom Baby's Financial Bust. Journal of Political Economy 87 (October 1979): 565-99. 


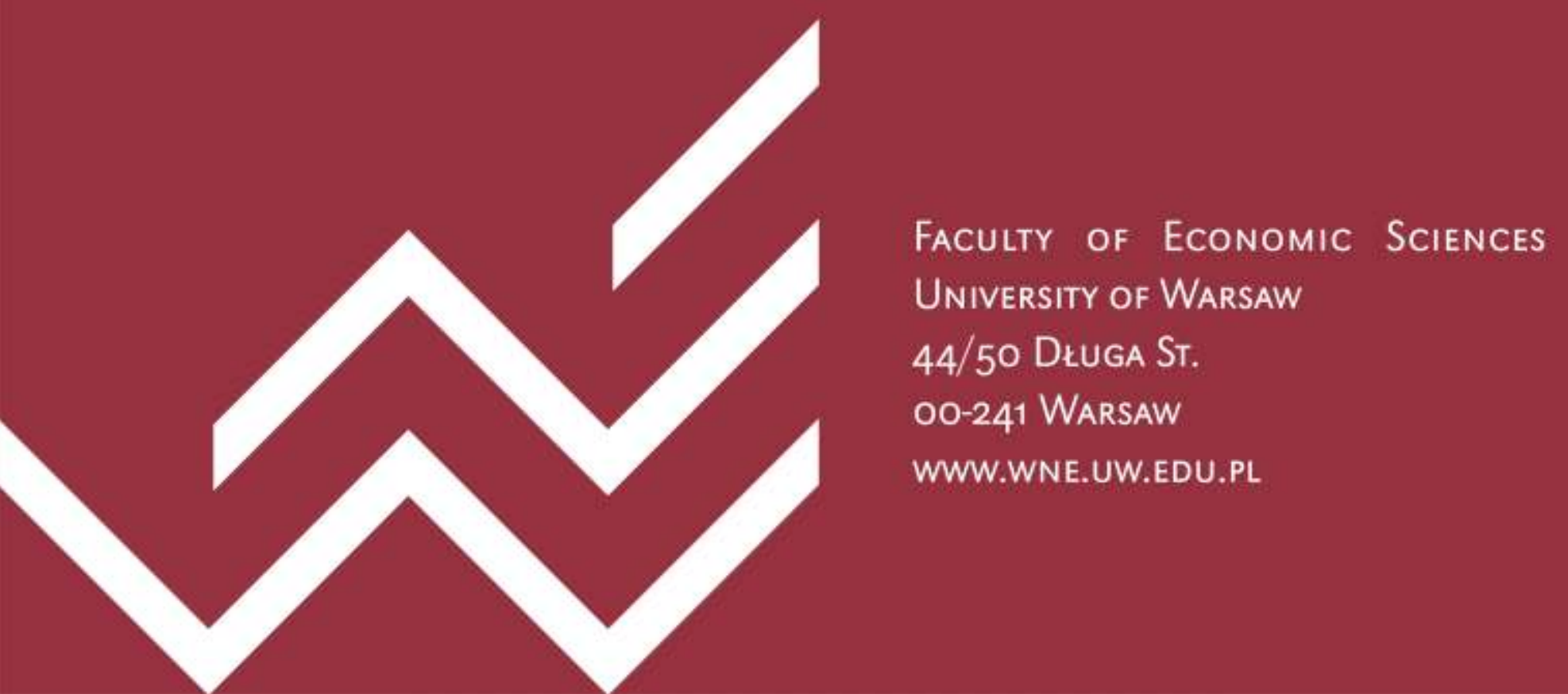

